\title{
Dyke-controlled chute canyon at Mendha on River Par, western India
}

\author{
A. D. Patil ${ }^{1}$, P. S. Hire ${ }^{2, *}$, M. K. Jaiswal ${ }^{3}$, G. W. Bramhankar ${ }^{2}$ and \\ K. Goswami ${ }^{3}$ \\ ${ }^{1}$ Department of Geography, RNC Arts, JDB Commerce and NSC Science College, Nashik 422 101, India \\ ${ }^{2}$ Department of Geography, HPT Arts and RYK Science College, Nashik 422 005, India \\ ${ }^{3}$ Department of Earth Sciences, Indian Institute of Science Education and Research, Kolkata 741 246, India
}

\begin{abstract}
Chute channels in rivers flowing on bedrock are uncommon and shaped under limited range of fluvial conditions. This study presents a mechanism of initiation and further development of a chute canyon in the Deccan Trap bedrock along the course of River Par in western India. Based on field evidences, OSL dating, hydraulics and resistivity of the dykes, we hypothesize that the morphology of the canyon is a result of interplay between flood-evoked excavation of a dyke by head-cut migration of gullies from the downstream end of the forming chute and downstream extension by undercutting process. Intermittent slope failure and plucking have contributed to the widening and deepening of the chute canyon.
\end{abstract}

Keywords: Bedrock, chute channel, dyke, meandering rivers, optically stimulated luminescence dating.

A primary process in the evolution of meandering rivers is the development of meander cut-off. Geometrically, cut-off reduces morphological complexity of the meandering rivers irrespective of whether they develop in old floodplains, bedrock, subtropical grasslands, tropical rainforests, permafrosts, desert edges, alpine meadows or even on $\mathrm{Mars}^{1-7}$. In general, there are two cut-off processes that give rise to meander cut-off, viz. neck cutoff and chute cut-off ${ }^{8,9}$. The neck cut-off is a process that results from bank collapse after maturing meanders have migrated into one another ${ }^{9,10}$. The chute cut-off occurs when floods incise a channel or chute that evolves into the dominant carrier of the river discharge $\mathrm{e}^{10,11}$. By definition, chute cut-off is the formation of a new channel across an inner bend sediment deposit or floodplain peninsula enclosed by a meander loop, which usually results in gradual closure of the abandoned channel by sedimentation $^{12}$. The new channel is called the chute channel and the abandoned channel as the chute cut-off. The term 'chute cut-off' is used when a stream reduces its length through cutting a new channel by following a swale or depression across the inside of a meander bend $^{12}$.

\footnotetext{
*For correspondence. (e-mail: pramodkumarhire@gmail.com)
}

In the published literature, the mechanisms of formation of chute cut-offs have received less attention compared to the neck cut-offs ${ }^{9,13-15}$. Three mechanisms have been proposed in the literature to explain chute cut-off formation, viz. embayment formation and extension ${ }^{5,16}$, head-cut propagation ${ }^{11,17,18}$ and swale enlargement ${ }^{5,19-22}$. A chute cut-off may form by one or more than one of these mechanisms ${ }^{16}$. Each mechanism requires specific conditions.

Chute channels and chute cut-off in the bedrock compared to alluvial channels are rare. They are uncommon features. To the best of our knowledge, chute channels in the bedrock have not been documented in the Indian subcontinent till date. However, occurrence of abundant loops and course-straightening in bedrock channels have been reported in the Narmada - the largest west-flowing river of India near Dardi, Madhya Pradesh, India ${ }^{23}$. We have observed a chute channel and well-preserved chute cut-off along River Par in Mendha village, Kaprada taluk, Balsad district, Gujarat. The chute cut-off has developed here in the Deccan Trap bedrock. The study of chute channel at Mendha comprises: (i) understanding the mechanism of formation of the unusual Mendha Chute Canyon (MCC), and (ii) to determine the date of initiation of the MCC and its further development. We hypothesize that the chute canyon was primarily initiated and further shaped by excavation of a NNW-SSE-oriented dolerite dyke.

\section{Physiographic settings}

The Par is a meandering river on the bedrock with an average sinuosity index ( $\mathrm{Si}$ ) of 1.74 . It flows for $142 \mathrm{~km}$ in western India (Figure 1). The study area on the river course is a NNW-SSE-oriented chute channel near Mendha village $\left(20^{\circ} 23^{\prime} 16.44^{\prime \prime} \mathrm{N}, 73^{\circ} 16^{\prime} 45.93^{\prime \prime} \mathrm{E}\right.$; Figure 1). We have named it as the 'Mendha Chute Canyon', as it is a canyon that has developed in a chute channel. The MCC is located $82.42 \mathrm{~km}$ downstream from the source of River Par which originates at $982 \mathrm{~m}$ amsl at Harantekdi, Maharashtra, India. Out of total 1664 sq. km area of the Par Basin, the upstream catchment area of the MCC is 


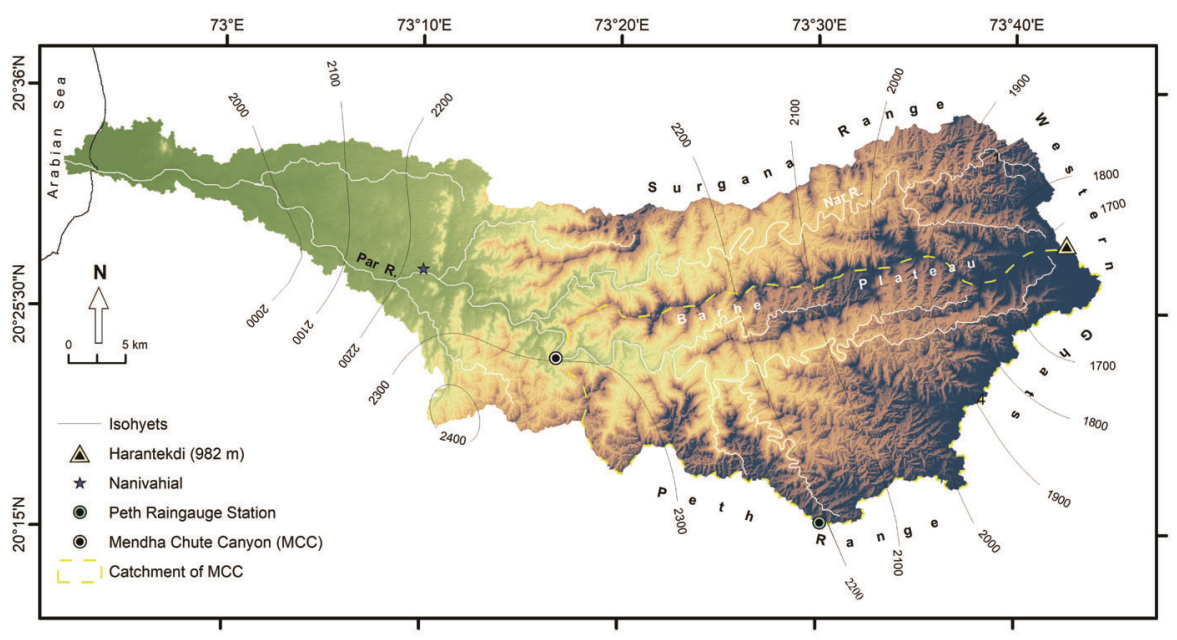

Figure 1. Physiographic map of the Par Basin in Western India.

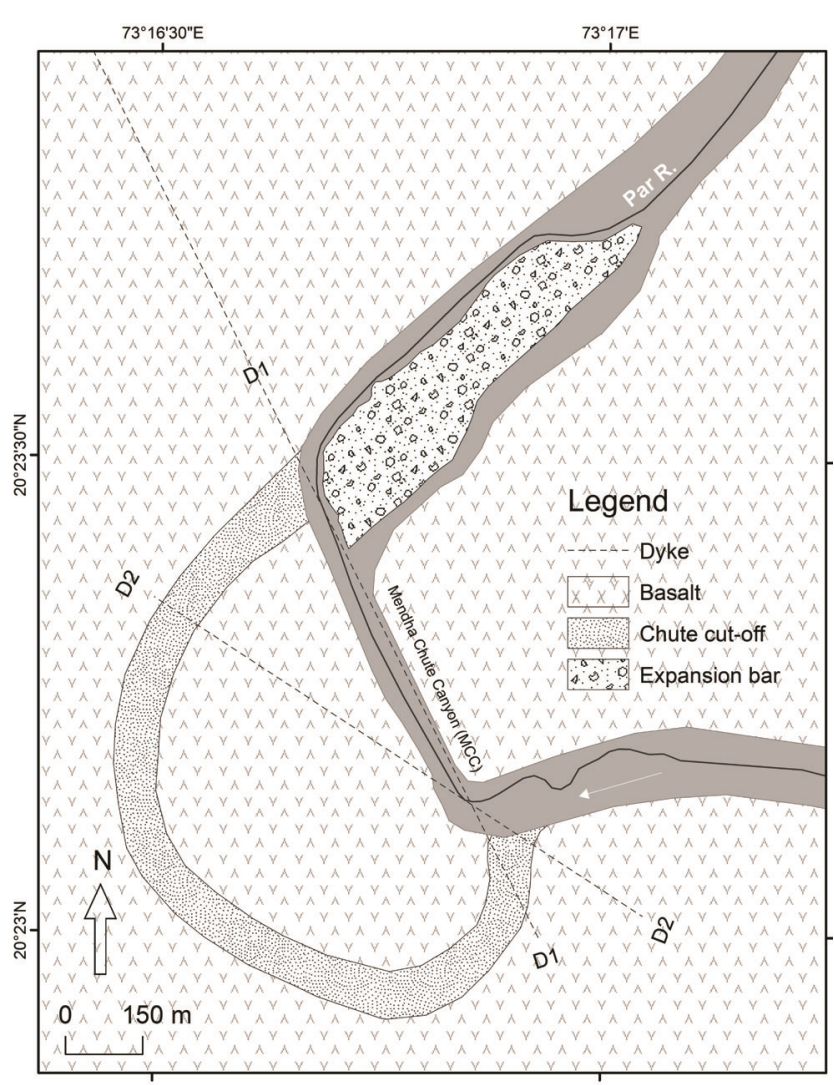

Figure 2. Geological map of the study area.

1207 sq. km (Figure 1). The geology of the study area comprises horizontally bedded Cretaceous Eocene Deccan Trap basalts and dykes (Figure 2). Field studies have highlighted eight morphological characteristics of the MCC.

(a) The MCC is remarkably linear for $600 \mathrm{~m}$, with almost vertical and relatively rough canyon walls (Figure 3 ).

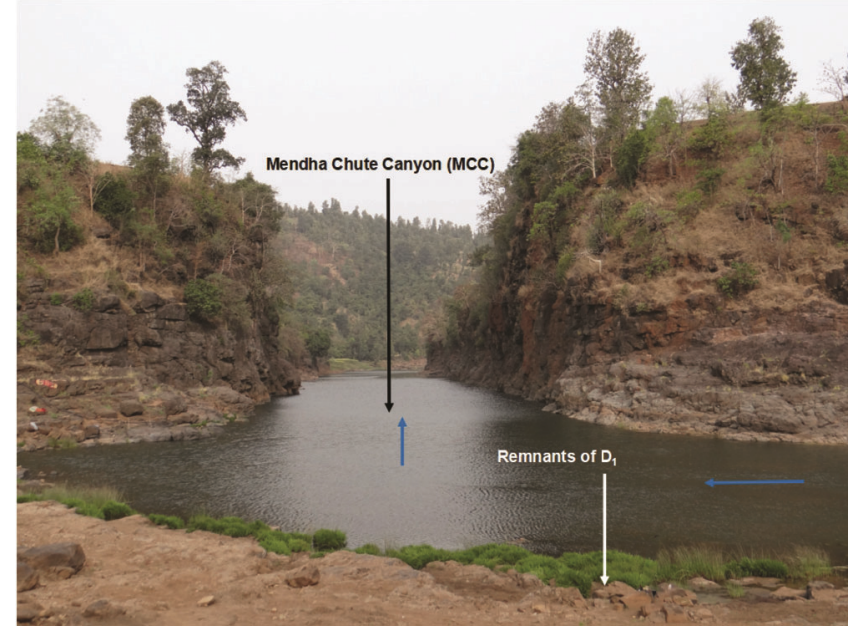

Figure 3. Photograph showing a cross view of the constricted Mendha Chute Canyon (MCC) and highly eroded dolerite Dyke $\left(D_{1}\right)$ at beginning of the MCC.

(b) The Par flows with smooth bends all through its course; nevertheless, at the MCC there is an anomalous angularity in the bend.

(c) The width-to-depth ratio of the MCC is remarkably small (depth $\geq$ width), i.e. 0.71 . This is mainly attributed to a narrow $(42 \mathrm{~m})$ and deep $(59 \mathrm{~m})$ channel, including a $9 \mathrm{~m}$ deep pool that contains water throughout the year (Figure 3).

(d) The MCC is vertically incised into a spur (Figure $4 a$ and $b$ ).

(e) The Par is notably wide, immediately upstream and downstream of the MCC. Maximum expansion of the channel is about seven times proximately downstream of the MCC, where a huge expansion bar (1.85 sq. km) has been formed with giant boulders (Figure $4 a$ ). The largest boulder with $6200 \mathrm{~mm}$ intermediate axis ( $i$-axis) is deposited at the beginning of expansion bar. 


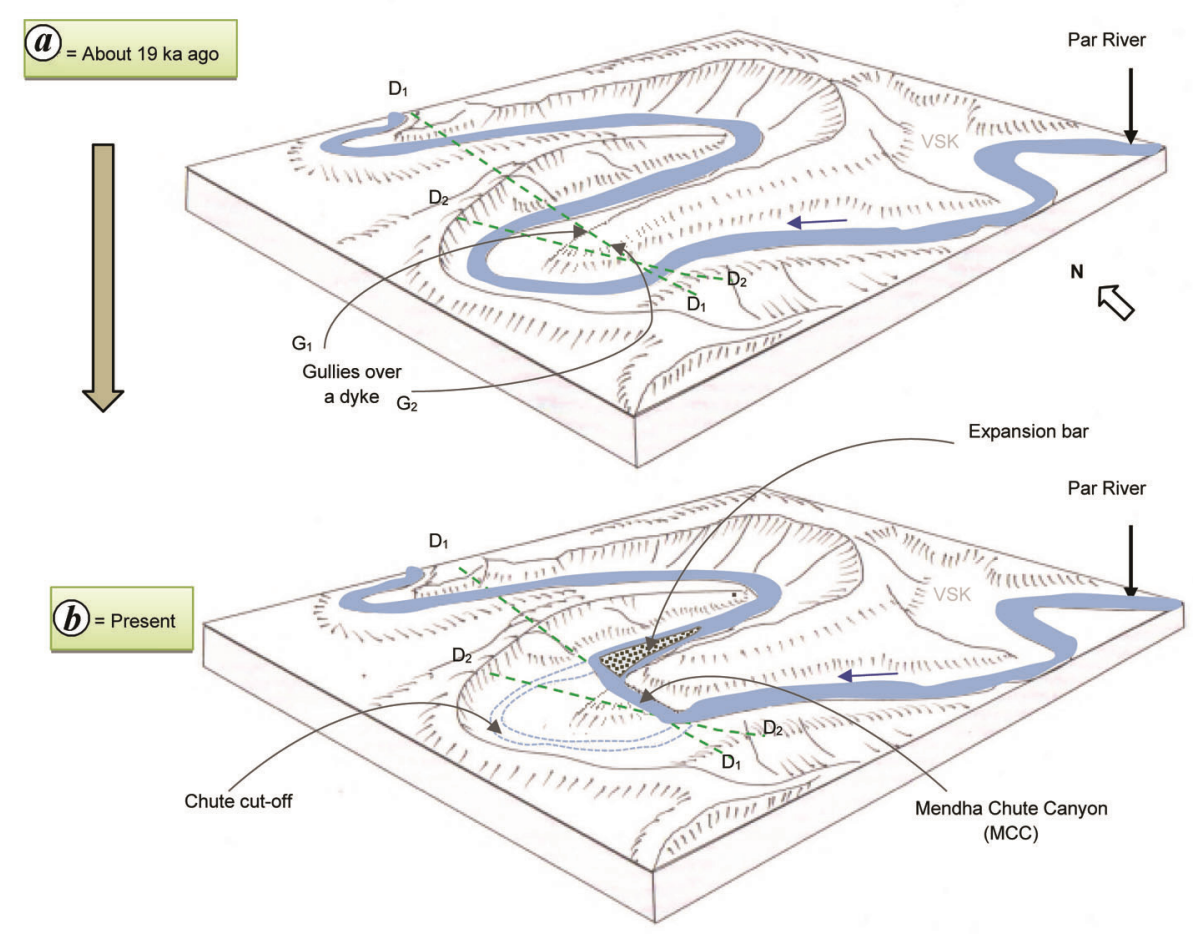

Figure 4. Block diagram showing stages in the formation of the MCC and chute cut-off. $\boldsymbol{a}$, Stream course before the formation of the MCC, about $19 \mathrm{ka}$ ago. $\boldsymbol{b}$, Present course of the MCC with the chute cut-off and expansion bar.

(f) The average gradient of the MCC is $0.00167 \mathrm{~m} / \mathrm{m}$, which is much steeper than alluvial reaches.

(g) A 3-4 m wide dolerite dyke-1 ( $\left.\mathrm{D}_{1}\right)$, with crude columnar joints occurs at the beginning of the MCC (Figure 3), oriented in the same direction of the canyon (NNW-SSE) (Figure 2). The dyke has also been traced downstream of the MCC and in an adjacent tributary of the Par, namely River Nar. Another (WNW-ESE) dolerite dyke-2 $\left(D_{2}\right)$ crosses $D_{1}$ at the beginning of the MCC. Remnants of $D_{1}$ and $D_{2}$ are observed on the canyon walls as well as on the bed.

An excellent, well-preserved chute cut-off with fine sediments on the bed has been disclosed at an elevation of $25 \mathrm{~m}$ from the bed of the MCC (Figure 4). The average gradient and length of chute cut-off are $0.0005 \mathrm{~m} / \mathrm{m}$ and $2 \mathrm{~km}$ respectively.

\section{Materials and methods}

The entire study is primarily based on field observations. A thorough evaluation of the hydraulic controls on chute incision is basic to a better understanding of how chute channels and chute cut-offs occur ${ }^{5}$. Therefore, to understand flood hydraulics and hydrodynamics of the MCC, cross-sectional and longitudinal profile auto-level surveys were carried out. In order to study the role of dykes in shaping the MCC, the Schmidt hammer rebound values $(N)$ were derived using $N$-type Schmidt hammer. The $N$ values were used to estimate the rock mass strength (RMS), i.e. the specific properties of the rock mass that control its strength ${ }^{24}$. We collected a sediment sample from the chute cut-off for optically stimulated luminescence (OSL) dating. Furthermore, textural analysis of the sediments has been carried out to understand its fluvial origin. In order to evaluate the mobility of the coarse sediments, theoretically from the MCC, the sedimenttransport equations were computed for the largest boulder deposited at the beginning of the expansion bar $^{25}$.

\section{Mechanisms for formation of the MCC}

The chute channels in bedrock rivers are rare and develop under limited range of fluvial conditions. The MCC has not been formed by the normal processes that occur on the floodplains of alluvial rivers. Moreover, it was not possible to form the chute canyon due to floods alone. Evidences to the probable mode of origin of the MCC are provided by the alignment and remarkable linearity of the canyon (distinctly seen on the SOI topographic map and satellite image of the area), presence of patches of dolerite dyke in the bed of the river and on the canyon walls, well-preserved chute cut-off and the dominance of coarse angular debris in the form of an expansion bar immediately downstream of the canyon. It is well-defined from the size, angularity and lithology of the boulders of the expansion bar and its proximity to the canyon that 
they are detached from the MCC. It is evident in the field that majority of the boulders (perhaps all) of the expansion bar have been derived by the detachment, frequent slope failures (rockfall), localized transportation and deposition downstream of the MCC.

It is noticeable from field observations that the MCC is mainly sculpted in a spur (Figure $5 a$ and $b$ ). The dotted contour lines of $115 \mathrm{~m}$, on both sides of the $\mathrm{MCC}$, represents a cut-spur. The aforesaid spur was continuous before the formation of the MCC. The curved line connecting points $A, B$ and $C$ represents chute cut-off (abundant meander) and the reach from points $A$ to $C$ shows the current path of the MCC. We have calculated slope of chute cut-off $(A-B-C)$ and the MCC $(A-C)$ by an autolevel survey to find the gradient. The gradient of the chute cut-off $(A-B-C)$ is $0.0005 \mathrm{~m} / \mathrm{m}$ and that of the MCC $(A-C)$ is $0.00167 \mathrm{~m} / \mathrm{m}$.

In order to determine date of the event of the last exposure of sediments to sunlight or burial ages at the chute cut-off, a sample was collected for OSL dating using the single aliquot regenerative-dose (SAR) protocols ${ }^{26,27}$. The age of the sediment sample is $19.577 \pm 0.958 \mathrm{ka}$ implying that the deposits were laid down over a span of the Middle Pleistocene during the last glacial maximum (LGM) stretching from 12 to $25 \mathrm{ka}$ centred on $\sim 21 \mathrm{ka}$. It, therefore, suggests that the channel was active during this period and an excavation of the MCC must have occurred primarily after the Middle Pleistocene. In this connection, it is interesting to note that the formation of the MCC is associated with early Holocene Climatic Optimum ( 9$7 \mathrm{ka}$ ) and stronger monsoon/rapid rise in sea level ${ }^{28-31}$. $\mathrm{We}$, therefore, propose that the MCC is mainly shaped due to infrequent large-magnitude floods of the Holocene, with immense competence. The formation of the MCC and plugging of the chute cut-off proceeded concurrently and gradually. The chute cut-off was active during the dated period $(19.577 \pm 0.958 \mathrm{ka})$, and deposited sediments until terminal closure of the chute cut-off was complete.

In order to understand depositional environmental conditions of the chute cut-off, a sediment sample was collected for textural analysis. The sediment of chute cut-off belong to mainly dark yellowish-brown (10 year $4 / 4)$ hue group, according to Munsell notation. The textural characteristics of the sediment noticeably suggested the composition of fine sand to clay on the Udden-Wentworth scale, indicating that the sediment is of fluvial origin.

It is important to understand the triggering mechanisms for the formation of the MCC. Absence of remnants of potholes or grooves on the canyon bed and walls suggests that the normal processes of vertical erosion or downcutting through potholes have not contributed to the shaping of this canyon. In fact, the presence of dykes at the beginning, on the wall and at the end of the MCC, and huge blocks of dyke deposited downstream of the MCC support the hypothesis that the latter was primarily initiated and further shaped by excavation of the NNWSSE-oriented dolerite dyke $\left(\mathrm{D}_{1}\right)$ (Figure $4 a$ and $b$ ). A strong and unequivocal evidence to support the abovementioned process, i.e. formation of canyon by excavation of the dyke is the Sandan Slot Canyon (SSC) on the crest of the Western Ghat in the Deccan Traps ${ }^{32}$. Furthermore, a similar process is in operation at Chornali Juvenile Slot Canyon in the close vicinity of SSC and Nane Ghat at the source of River Kukadi ${ }^{32}$. Thus, there is little doubt that the MCC has been formed mainly by the excavation of a dyke. Moreover, the coarse sediments, predominantly made of non-dyke material, at the expansion bar suggest that intermittent slope failures have contributed in the widening of the canyon after removal of the dyke.

We anticipate that the excavation of the MCC must have started by extension and headward erosion of gullies $\left(G_{1}\right.$ and $\left.G_{2}\right)$, originated over the spur from the opposite sides along $\mathrm{D}_{1}$ (Figure $4 a$ and $b$ ). Gradually, the headcuts migrated from the downstream end of the forming chute, progressively capturing an increasing fraction of the over-bank flow and finally causing the cut-off of the original bend. Concurrently, the process of downstream extension by undercutting might have operated at the bottom of $\mathrm{G}_{1}$. The inception of the MCC was controlled by shear stress distribution at the outer bank, downstream of a bend apex (Figure $4 a$ and $b$ ). For about $1 \mathrm{~km}$ upstream of point $A$, the channel was straight and before the formation of the MCC, there was an abrupt curve after point $A$ (Figure $5 a$ ). As a result, downstream extension process was initiated by concentration of in-channel flow velocity and shear stresses at the outer bank (from where the present MCC begins). The process was accelerated due to existence and junction of $D_{1}$ and $D_{2}$ at the bottom of $G_{1}$ (Figure $4 a$ and $b$ ). $D_{2}$, compared to $\mathrm{D}_{1}$, is highly resistant (rock mass strength $=82.3 \mathrm{~N} / \mathrm{mm}^{2}$ ); therefore, due to incessant operation of the process, the channel was gradually shifted by excavating relatively less-resistant $D_{1}$ (rock mass strength $=66.77 \mathrm{~N} / \mathrm{mm}^{2}$ ). Eventually the loop $(A-B-C)$ was short-circuited and the new channel $(A-C)$ was carved.

Field evidences show that the erosion mechanism was excavation of the dyke material predominantly by plucking (also known as quarrying and jacking), rather than abrasion. The joint-bounded columns are susceptible to plucking-type erosion in which the pressure fluctuations associated with vertical vortices (kolks) lift sections of the columns ${ }^{33}$. The remnants of $\mathrm{D}_{1}$ and $\mathrm{D}_{2}$ observed on the bed and wall at the beginning of the MCC, display crude columnar jointing. The prominent horizontal joints have distinctly favoured the removal of joint-defined dyke blocks by hydraulic forces. Likewise, strong hydraulic forces are produced within the narrow MCC during high-magnitude floods following heavy monsoon rainfall. The canyon catchment with $1207 \mathrm{sq} . \mathrm{km}$ area, receives abundant monsoon rainfall, e.g. the average 

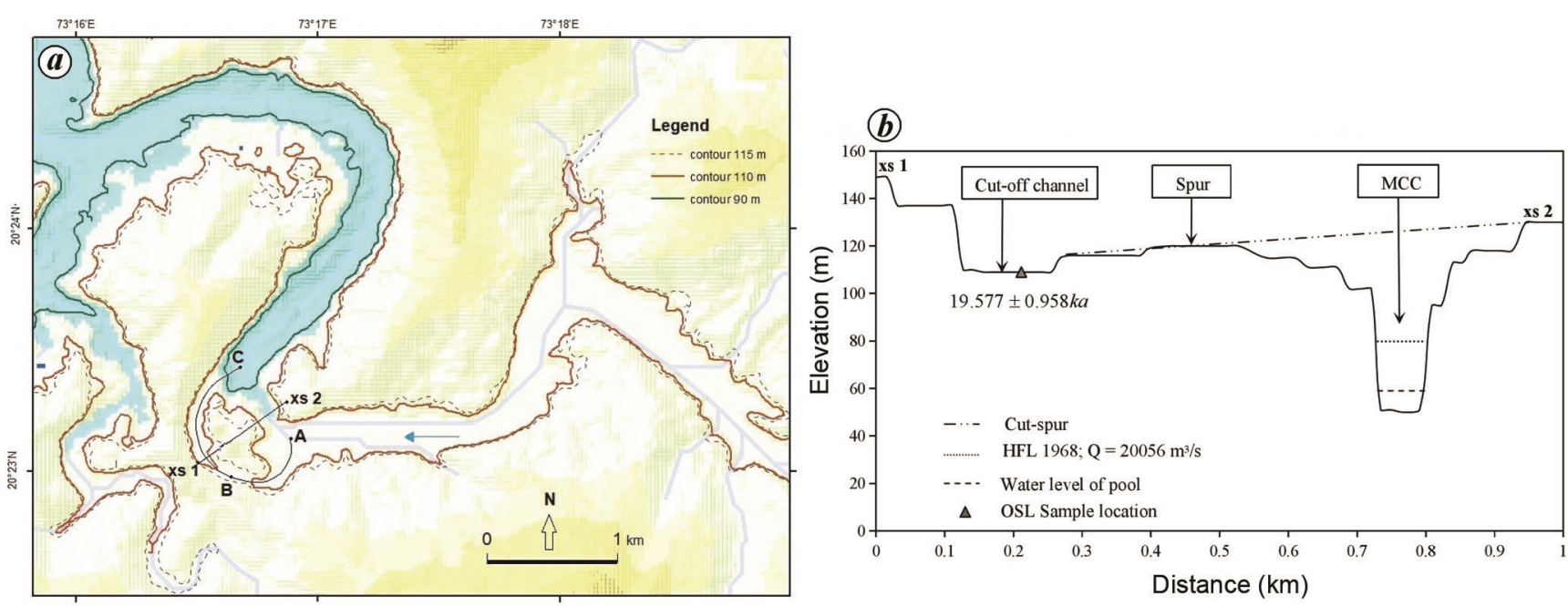

Figure 5. a, Chute cut-off (ABC) and the $\mathrm{MCC}(\mathrm{AC})$. The line xs 1-xs 2 represents reference for cross-profile. $\boldsymbol{b}$, Cross profile across the chute cut-off and the MCC. Note the elevated portion of spur between the chute cut-off and the MCC; ka, kilo annus (thousand years before present); OSL, optically stimulated luminescence; HFL, high flood level; Q, discharge.

annual rainfall at Peth raingauge station is $2603 \mathrm{~mm}$ (Figure 1), which is mainly confined to the monsoon months (June-September) and occurs in multiple wet spells ${ }^{34}$.

In order to understand the role of hydraulic forces generated during high-magnitude floods, we have estimated hydraulic parameters such as boundary shear stress $(\tau)$, stream power per unit area $(\omega)$, Froude number (Fr) and Reynolds number (Re) for the well-known 1968 catastrophic flood event with the help of the following equations ${ }^{35,36}$

$$
\begin{aligned}
& \tau=\gamma R S, \\
& \omega=\gamma Q S / w, \\
& \operatorname{Fr}=\bar{v} /(g R)^{0.5}, \\
& \operatorname{Re}=\bar{v} R / v,
\end{aligned}
$$

where $\tau$ is the boundary shear stress $\left(\mathrm{Nm}^{-2}\right), \gamma$ the specific weight of clear water $\left(9800 \mathrm{Nm}^{-3}\right), R$ the hydraulic radius or mean depth of water (m), $S$ the channel slope, $\omega$ the unit stream power $\left(\mathrm{Wm}^{-2}\right), Q$ the discharge $\left(\mathrm{m}^{3} \mathrm{~s}^{-1}\right), w$ the water surface width $(\mathrm{m})$, Fr the Froude number, $\bar{v}$ the mean flow velocity $\left(\mathrm{m} \mathrm{s}^{-1}\right), g$ the acceleration due to gravity $\left(9.8 \mathrm{~ms}^{-2}\right)$, Re the Reynolds number, $v$ is the kinematic viscosity $\left(1 \times 10^{-7} \mathrm{~m}^{2} \mathrm{~s}^{-1}\right.$ for water temperature of $\left.20^{\circ} \mathrm{C}\right)^{35,37}$.

Another related measure of erosional power of flows is the critical velocity for initiating cavitation $\left(V_{c}\right)^{38,39}$

$$
V_{\mathrm{c}}=2.6(10+D)^{0.5} \text {, }
$$

where $V_{\mathrm{c}}$ is the critical velocity for the inception of cavitation $\left(\mathrm{m} \mathrm{s}^{-1}\right)$ and $D$ is the flow depth $\left(\mathrm{m} \mathrm{s}^{-1}\right)$.
The existence of large boulders deposited downstream of the MCC, in the form of an expansion bar, provides some clue to the competence of the flows. In order to theoretically evaluate the mobility of the coarse sediment deposited immediately downstream of the MCC (Figure 2) the sediment-transport equations were used and the approximate minimum critical values of unit stream power $(\omega)$, bed shear stress $(\tau)$ and mean velocity $(\bar{v})$ that could initiate cobble and boulder movement were estimated. The equations used in the boulder transport calculations are as follows ${ }^{25}$

$$
\begin{aligned}
& \omega=0.079 d_{\mathrm{g}}^{1.27}, \\
& \tau=0.17 d_{\mathrm{g}}, \\
& \bar{v}=0.065 d_{\mathrm{g}}{ }^{0.5},
\end{aligned}
$$

where $d_{\mathrm{g}}$ is the intermediate diameter of the grain ( $\left.\mathrm{mm}\right)$.

The August 1968 flood is recognized as the largest ever recorded event in the basin with a magnitude of $23,820 \mathrm{~m}^{3} \mathrm{~s}^{-1}$ Nanivahial, Gujarat (Figure 1). This event has produced flooding with magnitude of $20,056 \mathrm{~m}^{3} \mathrm{~s}^{-1}$ at the MCC. The estimated values of mean velocity, bed shear stress and unit stream power per unit boundary area of the August 1968 flood for the MCC are $16.62 \mathrm{~m} \mathrm{~s}^{-1}$, $2306 \mathrm{Nm}^{-2}$ and $38,322 \mathrm{Wm}^{-2}$ respectively. According to anecdotal evidence, a huge boulder with $6200 \mathrm{~mm} i$-axis was detached from the bed at the middle of the MCC and deposited $\sim 350 \mathrm{~m}$ from its initial location during the August 1968 catastrophic flood event. The theoretical values of mean velocity, bed shear stress and unit stream power required for entrainment of this boulder are $5.12 \mathrm{~m} \mathrm{~s}^{-1}, 1054 \mathrm{Nm}^{-2}$ and $5176 \mathrm{Wm}^{-2}$ respectively. The estimated values of these variables are several orders of 


\section{RESEARCH ARTICLES}

magnitude higher for the August 1968 catastrophic flood event. Therefore, the Par was capable of moving the boulder with $6200 \mathrm{~mm} i$-axis during the August 1968 catastrophic flood event. Such strong, high-magnitude floods in the MCC are capable of dislodging blocks of jointed rocks from the canyon side-walls due to rockfall (channel boundary), and transport them to the depositional site downstream. The accumulation of angular boulders at the expansion bar supports this inference. The analysis further shows that cavitation had occurred at the MCC during the August 1968 flood, as the critical velocity required for inception of cavitation is $16.12 \mathrm{~ms}^{-1}$; however, the estimated velocity for the 1968 catastrophic event is $16.62 \mathrm{~ms}^{-1}$. Such extraordinary floods following torrential monsoon rainfall and intense fluvial erosion, predominantly plucking, are significant in sculpting the MCC.

Thus, shaping of the MCC appears to be a four-stage process: (i) Excavation of dyke initiated by extension and headward erosion of gullies and downstream extension by undercutting, mainly due to strong hydraulic forces induced by high monsoon runoff. (ii) Excavation process propagated upstream along the dyke and migration of the head-cuts from the downstream end of the developing chute. Eventually this result in short-circuiting of loop and carving of a new channel. (iii) Extraordinary floods following torrential monsoon rainfall and intense fluvial erosion, predominantly by plucking, are significant in the sculpting the MCC. (iv) The unstable, exposed, nearvertical walls occasionally fail and contribute huge rocky blocks to the canyon bottom and expansion bar.

\section{Conclusion}

This article explains the formation of the uncommon MCC on the basis of recent studies of the position of chute cut-off, location of dykes, well-sorted, fine-grained sediment of the chute cut-off and its date, coarse sediment deposited immediately downstream of the MCC, and flood hydraulics and hydrodynamics. The principal inference is that the MCC was initiated and further shaped due to excavation of a dyke by high-magnitude monsoon floods. The formation of the uncommon MCC in the bedrock has been ascertained by an unusual association of site-specific factors (geological, climatic, hydrological and geomorphological).

1. Lonsdale, P. and Hollister, C. D., Cut-offs at an abyssal meander south of Iceland. Geology, 1979, 7, 597-601.

2. Wasklewicz, T. A., Anderson, S. and Liu, P. S., Geomorphic context of channel locational probabilities along the Lower Mississippi River, USA. Geomorphology, 2004, 63, 145-158.

3. Deptuck, M. E., Sylvester, Z., Pirmez, C. and O'Byrne, C., Migration-aggradation history and $3 \mathrm{D}$ seismic geo-morphology of submarine channels in the Pleistocene Beninmajor Canyon, western Niger Delta slope. Mar. Pet. Geol., 2007, 24, 406-433.
4. Finnegan, N. J. and Dietrich, W. E., Episodic bedrock strath terrace formation due to meander migration and cutoff. Geology, 2011, 39, 143-146.

5. Constantine, J. A., McLean, S. R. and Dunne, T., A mechanism of chute cutoff along large meandering rivers with uniform floodplain topography. Geol. Soc. Am. Bull., 2010, 122, 855-869.

6. Matsubara, Y., Howard, A. D., Burr, D. M., Williams, R. M., Dietrich, W. E. and Moore, J. M., River meandering on Earth and Mars: a comparative study of Aeolis Dorsa meanders, Mars and possible terrestrial analogs of the Usuktuk River, AK, and the Quinn River, NV. Geomorphology, 2015, 240, 102-120.

7. Li, Z. W., Yu, G. A., Brierley, G., Wang, Z. Y. and Jia, Y. H., Migration and cutoff formation of meanders in hyper-arid environments of the middle and lower Tarim River, Northwestern China. Geomorphology, 2017, 276, 116-124.

8. Lewis, G. W. and Lewin, J., Alluvial cutoffs in wales and the Borderlands. In Modern and Ancient Fluvial Systems (eds Collinson, J. D. and Lewin, J.), Blackwell Publishing Ltd, Oxford, UK, 1983, vol. 6, pp. 145-154.

9. Gagliano, S. M. and Howard, P. C., The neck cutoff oxbow lake cycle along the Lower Mississippi River. In River Meandering (ed. Elliott, C.), American Society of Civil Engineers, New York, 1984, pp. 147-158.

10. Hooke, J. M., River channel adjustment to meander cutoffs on the River Bollin and River Dane, north-west England. Geomorphology, 1995, 14, 235-253.

11. Gay, G. R., Gay, H. H., Gay, W. H., Martinson, H. A., Meade, R. H. and Moody, J. A., Evolution of cutoffs across meander neck in Powder River, Montana, USA. Earth Surf. Proc. Landf., 1998, 23, 651-662.

12. Eekhout, J. P. C. and Hoitink, A. J. F., Chute cutoff as a morphological response to stream reconstruction: the possible role of backwater. Water Resour. Res., 2015, 51, 3339-3352.

13. Crickmay, C. H., Lateral activity in a river of northwestern Canada. J. Geol., 1960, 68, 377-391.

14. Ratzlaff, J. R., Development and cutoff of Big Bend meander, Brazos River, Texas. Texas J. Sci., 1981, 33, 121-129.

15. Erskine, W., McFadden, C. and Bishop, P., Alluvial cutoffs as indicators of former channel conditions. Earth Surf. Proc. Landf., 1992, 17, 22-37

16. Kleinhans, M. G. and van den Berg, J. H., River channel and bar patterns explained and predicted by an empirical and a physics-based method. Earth Surf. Proc. Landf., 2011, 36, 721-738.

17. Zinger, J. A., Rhoads, B. L. and Best, J. L., Extreme sediment pulses generated by bend cutoffs along a large meandering river. Nature Geosci., 2011, 4, 675-678.

18. Zinger, J. A., Rhoads, B. L., Best, J. L. and Johnson, K. K., Flow structure and channel morphodynamics of meander bend chute cutoffs: a case study of the Wabash River, USA. J. Geophys. Res. Earth Surf., 2013, 118, 2468-2487.

19. Fisk, H. N., Fine-grained alluvial deposits and their effects on Mississippi River activity. Waterways Experiment Station, Vicksburg, Mississippi, USA, 1947.

20. Bridge, J. S., Smith, N. D., Trent, F., Gabel, S. L. and Bernstein, P., Sedimentology and morphology of a low-sinuosity river: Calamus River, Nebraska Sand Hills. Sedimentology, 1986, 33, 851-870.

21. Hickin, E. J. and Nanson, G. C., The character of channel migration on the Beatton River, northeast British Colombia, Canada. Geol. Soc. Am. Bull., 1975, 86, 487-494.

22. Grenfell, M., Aalto, R. and Nicholas, A., Chute channel dynamics in large, sand-bed meandering rivers. Earth Surf. Proc. Landf., 2012, 37, 315-331.

23. Gupta, A., Kale, V. S., Owen, L. A. and Singhvi, A. K., Late Quaternary bedrock incision in the Narmada river at Dardi Falls. Curr. Sci., 2007, 93(4), 564-567.

24. Goudie, A. S. (ed.), Encyclopedia of Geomorphology, Taylor and Francis Group, Routledge, New York, 2004, vol. 1, pp. 57-58. 
25. Williams, G. P., Paleohydrological methods and some examples from Swedish fluvial environments. I. Cobble and boulder deposits. Geogr. Ann. A, 1983, 65, 227-243.

26. Murray, A. S. and Wintle, A. G., Luminescence dating of quartz using an improved single aliquot regenerative-dose protocol. Radiat. Meas., 2000, 32(1), 57-73.

27. Murray, A. S. and Wintle, A. G., The single aliquot regenerative dose protocol: potential for improvements in reliability. Radiat. Meas., 2003, 37(4), 377-381.

28. Pawar, N. J., Kale, V. S., Atkinson, T. C. and Rowe, P. J., Early Holocene waterfall tufa from semi-arid Maharashtra Plateau, India. J. Geol. Soc. India, 1988, 32, 513-515.

29. Kale, V. S., Ely, L. L., Enzel, Y. and Baker, V. R., Geomorphic and hydrologic aspects of monsoon floods on the Narmada and Tapi Rivers in central India. Geomorphology, 1994, 10, 157-168.

30. Sarkar, S., Prasad, S., Wilkes, H., Riedel, N., Stebich, M., Basavaiah, N. and Sachse, D., Monsoon source shifts during the drying mid-Holocene: biomarker isotope based evidence from the core 'monsoon zone' (CMZ) of India. Quaternary Sci. Rev., 2015, 123, $144-157$.

31. Limaye, R. B., Padmalal, D. and Kumaran, K. P. N., Late Pleistocene-Holocene monsoon variations on climate, landforms and vegetation cover in southwestern India: an overview. Quaternary Int., 2017, 443, 143-154.

32. Hire, P. S., Patil, A. D. and Kale, V. S., The Sandan slot canyon in the Deccan Traps: its morphology and mode of origin. Curr. Sci., 2019, 117(11), 1892-1896.

33. Baker, V. R., The channeled scabland: a retrospective. Annu. Rev. Earth Planet. Sci., 2009, 37, 393-411.

34. Patil, A. D. and Hire, P. S., Flood hydrometeorological situations associated with monsoon floods on the Par River in Western India. Mausam, 2020, 71, 687-698.
35. Leopold, L. B., Wolman, M. G. and Miller, J. P., Fluvial Processes in Geomorphology, Dover Publications, Inc, New York, USA, 1964.

36. Baker, V. R. and Costa, J. E., Flood power. In Catastrophic Flooding (eds Mayer, L. and Nash, D.), Allen and Unwin, London, UK, 1987, pp. 1-21.

37. Petts, G. E. and Foster, I. D. L., Rivers and Landscape, Edward Arnold, London, UK, 1985.

38. Baker, V. R., Erosional forms and processes for the catastrophic Pleistocene Missoula floods in the eastern Washington. In Fluvial Geomorphology (ed. Morisawa, M.), Geomorphology Publications, State University of New York, Binghamton, USA, 1973, pp. 123-148.

39. Patil, A. D., Hire, P. P. and Hire, P. S., Hydrologic and geomorphic aspects of high-magnitude floods on the Par River in western India. Hydrospat. Anal., 2017, 1(1), 3-8.

ACKNOWLEDGEMENTS. This work was carried out under research projects supported by the Board of College and University Development (BCUD), Savitribai Phule Pune University (SPPU), Pune (grant no. 14SCI000138). We thank Prof. Vishwas S. Kale for critical and constructive comments. We also thank Rajendra Gunjal, Uttam Pawar and the local villagers for their support in the field, and the Editor, Current Science for useful suggestions.

Received 18 November 2020; revised accepted 11 February 2021

doi: $10.18520 / \mathrm{cs} / \mathrm{v} 120 / \mathrm{i} 9 / 1507-1513$ 